\title{
DEVELOPMENT OF TWO-TEMPERATURE MATHEMATICAL MODEL OF PROCESSES IN DISCHARGE CHAMBER OF MULTI-CHAMBER ARRESTER OPERATING IN CONDITIONS OF MOUNTAIN AREAS
}

\author{
V. Frolov ${ }^{a, *}$ \\ D. IVANOV ${ }^{a}$ \\ A. SIVAEV ${ }^{b}$ \\ A. $\mathrm{ChusOv}^{b}$ \\ a Peter the Great St. Petersburg Polytechnic University, Polytechnicheskaya, 29, 195251, St. Petersburg, Russia \\ ${ }^{b}$ Streamer Electric AG, Nevsky Prospect, 147, 191024, St. Petersburg, Russia \\ * frolov.eed@gmail.com
}

\begin{abstract}
This article is devoted to a development of a mathematical model of plasma processes in a discharge chamber of a multi-chamber arrester operating under reduced pressure. The results obtained using this model will make it possible to develop recommendations on modifying the design of multi-chamber arresters for operation in conditions of mountain areas. A composition, thermodynamic and transport properties of plasma for the two-temperature model were calculated on the basis of the data on the materials of the discharge chamber and on the basis of the experiments performed earlier. The paper presents the results of calculations i.e. distributions of discharge voltage and electrical conductivity on time at various pressures. A comparison of obtained results was carried out.
\end{abstract}

Keywords: 2T model, simulation, pulse arc discharge, multi-chamber arrester.

\section{Introduction}

Protection of important energy facilities from direct lightning impact requires the creation of special devices for lightning protection.

Currently, a new promising way to protect overhead power lines from lightning impact is the use of multi-chamber arresters [1-3]. The multi-chamber arrester consists of a large number of series-connected chambers in which an arc discharge occurs during breakdown (Figure 1). Such a discharge is accompanied by erosion of the electrodes material and ablation of the material of the discharge chamber. During that process an increased pressure occurs in the chamber leading to the formation of a plasma jet from the discharge chamber and to the extinction of the electric arc (Figure 2).

Investigations of the physical processes that take place inside such devices have been carried out over the years to improve the efficiency of multi-chamber arrester operation. Along with experimental methods [4], theoretical studies using mathematical modeling become widespread [5-10]. The data obtained during experiments are used in the mathematical model as initial data as well as for the purpose of correcting the model.

Currently, there is the problem of application of arresters for power lines located in mountain areas where in some cases the pressure may be $0.3-0.8$ of the atmospheric pressure. The extinction of an electric arc in the arresters under such conditions becomes difficult, which is caused by the stable maintenance of the arc under reduced pressure. Therefore, the creation of lightning arresters requires significant adjustments.

At reduced pressure plasma in the presence of an electric field is characterized by a disturbance of ther-

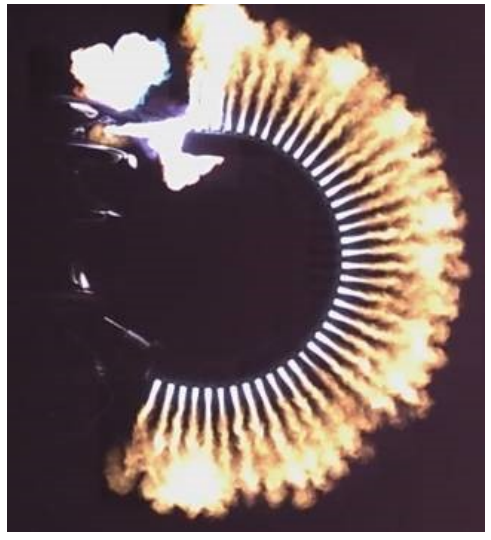

Figure 1. Discharge in a multi-chamber arrester.

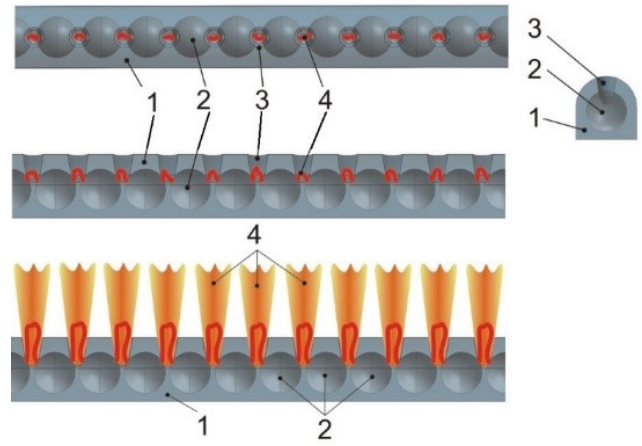

Figure 2. Arc discharges in a multi-chamber system: 1 - silicone rubber; 2 - electrodes; 3 - air gaps; 4 discharge channels.

mal equilibrium. Therefore, plasma in such conditions is more adequately described by the two-temperature model [11].

The purpose of this article is to develop a mathematical model of non-equilibrium plasma processes of a 
pulsed arc discharge of complex chemical composition using the example of processes in a discharge chamber of a multi-chamber arrester operating in mountainous areas.

\section{Methods}

\subsection{Calculation of plasma properties}

To develop a non-equilibrium mathematical model of a pulsed arc discharge it is necessary to know the thermodynamic and transport properties of a plasma as a function of electron temperature, heavy particle temperature, and pressure.

A method of calculation of the composition, thermodynamic and transport properties of both equilibrium and two-temperature plasma is described in sufficient detail in the references [11-15].

In the case of the two-temperature approximation the plasma composition depends on the electron temperature $T_{\mathrm{e}}$, the temperature $T_{\mathrm{h}}$ of the heavy species and the pressure $p$. In practice, the dependence of plasma composition on temperature $T_{\mathrm{e}}$ and the parameter $\theta=T_{\mathrm{e}} / T_{\mathrm{h}}$ is usually calculated at constant pressure.

The method of formation a system of equations describing composition in a chemically reacting medium is usually founded on two different approaches, one of which is based on the equations of mass action law using equilibrium constants [13, 14], and the other one - on finding the minimum of the thermodynamic potential of the system $[11,12]$. The first method was chosen for calculation.

Silicone rubber has the following chemical formula:

$$
\left(\mathrm{C}_{2} \mathrm{H}_{6} \mathrm{SiO}\right)_{\mathrm{n}}
$$

Using this information and considering possible cases of the electrode material $(\mathrm{Cu}, \mathrm{W}, \mathrm{Fe})$ the 85 components were taken into calculation.

The equilibrium constants for the equations of the mass action law were taken from $[16,17]$, and the partition functions of atoms and ions were calculated based on NIST data [18]. Enthalpies of individual components were taken from $[16,17]$ to calculate the thermodynamic properties.

To calculate the transport properties, it is necessary to find data on collision cross sections for each pair of species. The book [19] was used as the main source for specifying collisions between two neutral species and between neutral and charged components. If the required cross section was not found in the book [19] then we acted as follows.

When considering collisions between two neutral components it was assumed that the cross section can be described by the Lennard-Jones interaction potential [20], the main interaction parameters were taken from [21, 22] using rules given in [22].

When considering collisions between neutral and charged components it was assumed that the cross section can be described by the polarization potential, the parameters of which were taken from [21, 22].

The collision of two charged components was described by a screened Coulomb potential [23].

A series of calculations were carried out for a pressure range of $0.3-1.0 \mathrm{~atm}$ and a temperature range of $1000-30000 \mathrm{~K}$ with the following proportions of basic chemical elements included into the system:

$$
\mathrm{Si}: \mathrm{O}: \mathrm{C}: \mathrm{H}=1: 1: 2: 6 ; \mathrm{Fe}: \mathrm{O}=1: 10 \text {. }
$$

These ratios were determined using a condition that the walls of the discharge chamber are made of silicone rubber and the electrodes are made of steel.

The ratio $\mathrm{Fe}: \mathrm{O}=1: 10$ was made on the basis of experimental studies namely a spectral analysis of the plasma jet at the outlet of the chamber of the multi-chamber arrester. Comparison of the results of subsequent calculations with experimental data of electrical parameters of the discharge confirms the obtained ratio Fe:O.

The obtained dependences of plasma properties on the electron temperature and the heavy particles temperature [24] were used in the further mathematical model.

\subsection{Mathematical model}

A mathematical model of non-equilibrium plasma processes of a pulsed arc discharge in a discharge chamber of a multi-chamber arrester was developed using the software ANSYS Fluent.

In this paper, a two-temperature plasma model was used. This model was described in detail in [25], a chemical equilibrium was assumed. In addition to the equations of gas dynamics and the energy equation of heavy particles, which are standardly solved in ANSYS Fluent, the following equations were included into the mathematical model using the $U D F$ (user-defined functions) interface: the energy equation for electrons, the equation for scalar electric potential and the equation for vector magnetic potential [25].

A calculation domain including both the space inside the discharge chamber and the plasma jet region is shown in Figure 3. The task was solved in a twodimensional formulation.

The computational mesh consisted of 55000 triangular control volumes.

The boundary conditions were defined as follows. A value of scalar potential difference was set at the electrodes (Figure 3, boundaries 1) so that to provide the necessary discharge current (see below). The ablation of the walls of the discharge chamber was taken into account (Figure 3, boundaries 2), i.e. a source of mass was considered on the wall. Its value was calculated as follows.

The power $P_{\mathrm{pl}}$ transmitted from the plasma into the wall region $\Delta S$ due to thermal conductivity is determined by the formula:

$$
P_{\mathrm{pl}}=-\lambda \frac{\mathrm{d} T}{\mathrm{~d} n} \Delta S
$$




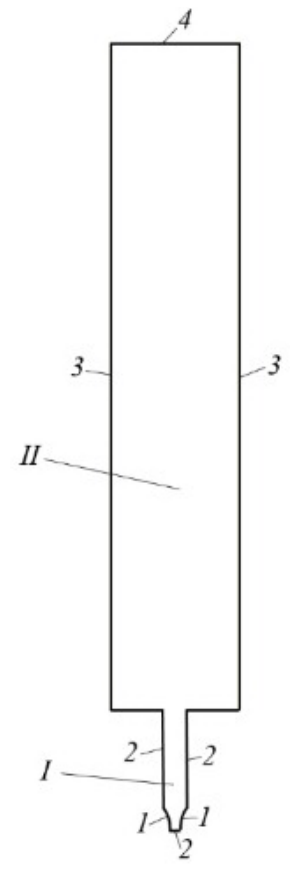

Figure 3. Calculation domain: I - the space inside the discharge chamber; II - the plasma jet region; 1 - electrodes; 2 - walls of the discharge chamber; 3 symmetry boundary; 4 - outlet (ambient pressure).

where $\lambda$ is thermal conductivity, $\mathrm{d} T / \mathrm{d} n$ is temperature gradient in the direction that is normal to the wall.

The energy consumption $P_{\text {vap }}$ for the evaporation of the wall material is determined by the formula:

$$
P_{\text {vap }}=\Delta H_{\text {vap }} \frac{\mathrm{d} m}{\mathrm{~d} t}
$$

where $\Delta H_{\text {vap }}$ is a specific heat of evaporation, $\mathrm{d} m / \mathrm{d} t$ is mass rate of evaporation that is source of mass for the calculation domain.

From the condition that all power transferred to the wall was spent on the evaporation of the wall material

$$
P_{\mathrm{pl}}=P_{\text {vap }}
$$

one can calculate a source of mass $\mathrm{d} m / \mathrm{d} t$.

Boundary 3 (see Figure 3) were considered as symmetry boundaries since the arrester has a multichamber design (it means that the same chambers are located to the left and right of the considered discharge chamber). The ambient pressure was set at the boundary 4 (Figure 3).

\section{Results}

Simulation was carried out for the time range from 0 to $250 \mu$ s for two cases: ambient pressure was $1 \mathrm{~atm}$ and $0.3 \mathrm{~atm}$.

In both cases the experimental dependence of the discharge current on time was used. To reduce the computation time, only the first $250 \mu \mathrm{s}$ and $150 \mu \mathrm{s}$ before current zero were used. The graph of the used

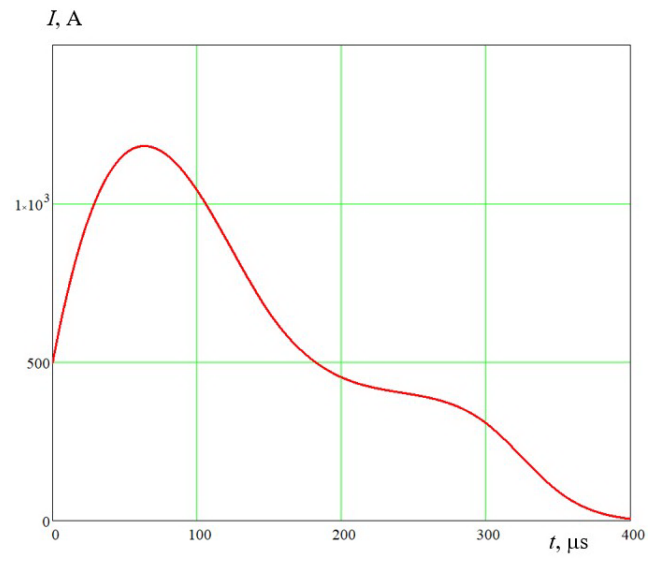

Figure 4. A dependence of the discharge current on time.

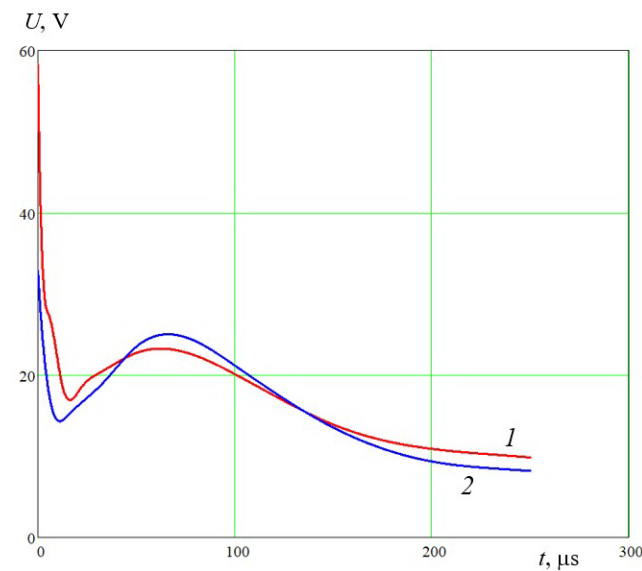

Figure 5. The dependence of the discharge voltage on time for operation at different pressures: 1 - $1.0 \mathrm{~atm}$, 2- $0.3 \mathrm{~atm}$.

dependence of the discharge current on time is shown in Figure 4.

The time dependences of the voltage providing the given current for pressure of $1 \mathrm{~atm}$ and $0.3 \mathrm{~atm}$ are shown in Figure 5. It is seen that at the end of the time dependences the voltage on the discharge chamber is greater in the case of a pressure of $1 \mathrm{~atm}$ than in the case of a pressure of $0.3 \mathrm{~atm}$. This suggests that with decreasing pressure the breaking capacity of multi-chamber arresters decreases.

A conductivity of the discharge gap (see Figure 6) was calculated on the base of the obtained data:

$$
G=\frac{I}{U}
$$

It can be seen (Figure 6) that at the end of the time dependences the conductivity of the discharge gap at a pressure of $0.3 \mathrm{~atm}$ is $20 \%$ higher than the conductivity at a pressure of $1 \mathrm{~atm}$.

Thus, the results of performed calculations showed that the conductivity of the discharge gap increased by $20 \%$ with a decrease in pressure from 1 to $0.3 \mathrm{~atm}$ (the range of pressure variation is due to the operating conditions of the arresters). This means that when 


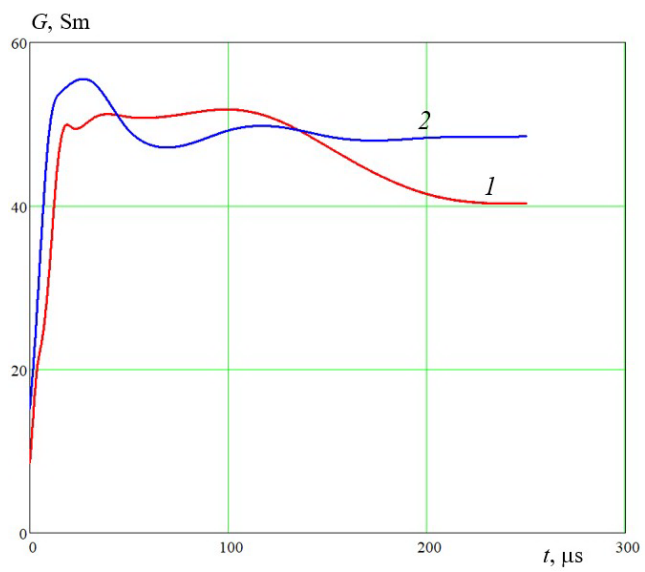

Figure 6. The dependence of the discharge conductivity on time for operation at different pressures: 1 - $1.0 \mathrm{~atm}$, 2 - $0.3 \mathrm{~atm}$.

the pressure decreases, conditions of the arc quenching degenerate.

Therefore, in order to increase the breaking capacity of multi-chamber arresters it is proposed to introduce insulating barriers into the regions of the discharge channel 4 (see Figure 2) between the electrodes. As a result, the length of the arc discharge will increase which contributes to an increase in evaporation of the chamber walls; the arc voltage increases which ultimately will increase the breaking capacity of a multi-chamber arrester.

It should also be noted that the investigating plasma processes have short time of existence. Under these conditions (high specific dissipated power, high arc velocity, reduced pressure) chemical reactions may not have time to finish, and chemical equilibrium may not be reached. Therefore, to clarify the characteristics of the breaking capacity of multi-chamber arresters it is necessary to improve the mathematical model, namely, to take into account the disturbance of chemical equilibrium.

\section{Conclusions}

Thus, the thermodynamic and transport properties of the plasma (air with vapors of materials of the discharge chamber wall and of electrodes material) were calculated and a two-dimensional two-temperature model of plasma processes in the discharge chamber of the multi-chamber arrester was developed. The calculation results showed a decreasing in the breaking capacity of the arrester by $20 \%$ with a decrease in pressure from 1 to $0.3 \mathrm{~atm}$. To increase the arrester's breaking capacity, it is proposed to introduce an insulating barriers into the regions of the discharge channel 4 (see Figure 2) between the electrodes.

To clarify the characteristics of the breaking capacity of multi-chamber arresters it is necessary to improve the mathematical model, namely, to take into account the disturbance of chemical equilibrium.

\section{References}

[1] G. Podporkin, E. Enkin, E. Kalakutsky, V. Pilshikov, and A. Sivaev. Lightning protection of overhead lines by multi-chamber arresters and insulator-arresters. In Proceedings of the 30th Int. Symp. on Lightning Protection, page 7845759, 2010. doi:10.1109/ICLP. 2010.7845759.

[2] R. Kozakov, A. Khakpour, S. Gorchakov, D. Uhrlandt, D. Ivanov, I. Murashov, G. Podporkin, and V. Frolov. Investigation of a multi-chamber system for lightning protection at overhead power lines. Plasma Physics and Technology, 2(2):150-154, 2015.

[3] G. Podporkin. Development of long flashover and multi-chamber arresters and insulator-arresters for lightning protection of overhead distribution and transmission lines. Plasma Physics and Technology, $2(3): 241-250,2015$.

[4] M. Pinchuk, A. Budin, I. Kumkova, A. Bogomaz, A. Sivaev, A. Chusov, and R. Zaynalov. Energy deposition in discharge chamber of lightning protection multichamber system. Journal of Physics: Conference Series, 774(1):012187, 2016. doi:10.1088/1742-6596/774/1/012187.

[5] V. Frolov, D. Ivanov, I. Murashov, and A. Sivaev. Calculation of the composition of plasma of an arc pulsed discharge in a multi-chamber arrester. Technical Physics Letters, 41(4):310-313, 2015. doi:10.1134/S1063785015040069.

[6] V. Frolov, D. Ivanov, I. Murashov, and A. Sivaev. Mathematical simulation of processes in discharge chamber of multi-chamber system for lightning protection at overhead power lines. In Proceedings of the 2016 IEEE North West Russia section young researchers in electrical and electronic engineering conference, ELCONRUSNW 2016, pages 562-565, 2016. doi:10.1109/EIConRusNW. 2016.7448245.

[7] A. Chusov, G. Podporkin, M. Pinchuk, D. Ivanov, I. Murashov, and V. Frolov. Development of a physical 2-D model for arc quenching chamber of lightning protection multichamber systems. In Proceedings of the 2016 33rd International Conference On Lightning Protection, ICLP 2016, page 7791509, 2016. doi:10.1109/ICLP. 2016.7791509.

[8] Z. Guo, X. Long, Z. Qian, and N. Qiu. Three dimensional simulation of the arc inside an insulator-arrester with a multichamber system. AIP Advances, 6(4):045117, 2016. doi:10.1063/1.4948453.

[9] V. Frolov, D. Ivanov, and R. Belsky. Increasing of operation security and of breaking capacity of surge arresters. In Proceedings of the 2017 IEEE Russia Section Young Researchers In Electrical And Electronic Engineering Conference, ELCONRUS 2017, pages 15201523, 2017. doi:10.1109/EIConRus. 2017.7910861.

[10] V. Frolov, D. Ivanov, G. Podporkin, and A. Sivaev. Development of mathematical model of processes in multi-chamber arrester for identification of criteria of arc extinction. In Proceedings of the 2017 International Symposium On Lightning Protection, XIV SIPDA 2017, 
pages $240-243,2017$.

doi:10.1109/SIPDA. 2017.8116930 .

[11] M. I. Boulos, P. Fauchais, and E. Pfender. Thermal Plasmas: Fundamentals and Applications. New York: Plenum, 1994.

[12] M. Capitelli, G. Colonna, and A. D'Angola. Fundamental Aspects of Plasma Chemical Physics: Thermodynamics. Springer Series on Atomic, Optical, and Plasma Physics. Springer-Verlag New York, 2012.

[13] V. P. Glushko et al. Thermodynamic and Thermophysical Properties of Combustion Products, Ed. by V. P. Glushko, Vol. 1. Nauka Moskva, 1971.

[14] A. Suris. Thermodynamics of High-Temperature Processes. Metallurgiya Moskva, 1985.

[15] V. Frolov and D. Ivanov. Calculation of a plasma composition and its thermophysical properties in cases of maintaining or quenching of electric arcs. Journal of Physics: Conference Series, page 012040, 2018. doi:10.1088/1742-6596/1058/1/012040.

[16] NIST atomic spectra database. Official cite. http: //physics.nist.gov/PhysRefData/ASD/index.html.

[17] V. P. Glushko et al. Thermodynamic Properties of Individual Substances: Reference Book, 3rd ed., Vols. 1-4. Nauka Moskva, 1978-1982.

[18] M. W. Chase Jr. NIST-JANAF Thermochemical Tables, Fourth Edition, Part I and II. Journal of Physical and Chemical Reference Data. 1998.

[19] M. Capitelli, D. Bruno, and A. Laricchiuta. Fundamental Aspects of Plasma Chemical Physics: Transport. Springer Series on Atomic, Optical, and Plasma Physics. Springer-Verlag New York, 2013.
[20] J. Hirschfelder, C. Curtiss, and R. Bird. Molecular theory of gases and Liquids. Wiley New York, 1954.

[21] Y. Cressault, R. Hannachi, P. Teulet, A. Gleizes, J.-P. Gonnet, and J.-Y. Battandier. Influence of metallic vapours on the properties of air thermal plasmas. Plasma Sources Science and Technology, 17(3):035016, 2008. doi : 10.1088/0963-0252/17/3/035016.

[22] P. Andre, J. Aubreton, S. Clain, M. Dudeck, E. Duffour, M. Elchinger, B. Izrar, D. Rochette, R. Touzani, and D. Vacher. Transport coefficients in thermal plasma. applications to mars and titan atmospheres. The European Physical Journal D, 57(2):227-234, 2010. doi:10.1140/epjd/e2010-00036-5.

[23] E. Mason, R. Munn, and F. Smith. Transport coefficients of ionized gases. The Physics of Fluids, 10(8):1827-1832, 1967. doi:10.1063/1.1762365.

[24] D. Ivanov, V. Skornyakov, I. Savelieva, M. Korotkikh, V. Shestakov, D. Uhrlandt, and G. Podporkin.

Mathematical simulation of operation of multi-chamber arrester for lightning protection of power lines: calculation of thermophysical properties of nonequilibrium plasma. In MATEC Web of Conferences, volume 245, page 07003, 2018. doi:10.1051/matecconf/201824507003.

[25] P. Freton, J. Gonzalez, Z. Ranarijaona, and J. Mougenot. Energy equation formulations for two-temperature modelling of 'thermal' plasmas. Journal of Physics D: Applied Physics, 45(46):465206, 2012. doi : 10.1088/0022-3727/45/46/465206. 